\title{
Educação para além da formação do trabalhador alienado
}

\section{Education beyond the formation of the alienated worker}

\author{
Natália Regina de Almeida ${ }^{1}$
}

\begin{abstract}
RESUMO
O objetivo principal deste trabalho é indicar algumas questões acerca do papel da educação frente à sociedade capitalista. É importante destacar que não se trata de um trabalho empírico, mas sim, de uma reflexão, uma tentativa de se pensar a relação educação-trabalho-capital. Nesse sentido, perguntamos: Qual o sentido da educação frente à lógica do capital? O papel da educação como "veículo" para novas propostas de elaboração de estratégias para a mudança consciente dos educandos é de fundamental importância. Para consolidar essa tentativa, utilizamos o apoio teórico de autores como: Gadotti (1995), Konder (1981), Marx (1983, 1989, 2002), Marx e Engels (1984, 1993), Mészáros (2005), Pires (1997) e Schaff (1967). Entendemos que uma educação que não seja meramente para formação de futuros "alienados", mas sim, uma educação que não se conforme com as reproduções sociais e que leve em consideração o caráter sócio-histórico do indivíduo, é crucial.
\end{abstract}

Palavras-chave: educação; trabalho; alienação.

\begin{abstract}
The main objective of this work is to indicate some questions concerning the role of education when it faces the capitalist society. It is important to emphasize that it is not an empirical work, but it comes from reflection, an attempt of thinking about the relation education-work-capital. In this direction, we ask: Which is the meaning of education when dealing with the logic of the capital? The education role as "vehicle" for new proposals of strategies elaboration for the conscientious change of learners is fundamentally important. In order to consolidate this attempt, we use the theoretical support of authors as: Gadotti (1995), Konder (1981), Marx (1983, 1989, 2002), Marx and Engels (1984, 1993), Mészáros (2005), Pires (1997) and
\end{abstract}

1 Mestranda do Programa de Pós-graduação em Educação da Universidade do Estado do Rio de Janeiro (ProPEd/ UERJ). Pedagoga formada pela Universidade do Estado do Rio de Janeiro (UERJ) - Componente do Núcleo de Estudo e Pesquisa em Epistemologia e Metodologia das Ciências - (EPISTEME / ProPEd). Universidade do Estado do Rio de Janeiro, Brasil. 
Schaff (1967). We understand that a kind of education that is not merely for formation of future "alienated" people, but the education that does not accept the social reproductions and that takes into consideration the socialhistorical character of the individual, is crucial.

Keywords: education; work; alienation.

A forma pela qual está sendo construído o mundo não tem sido a melhor maneira para o desenvolvimento e a formação dos indivíduos. Desemprego, miséria, crises econômicas, várias são as consequências que contribuem para a criação de uma cultura de "exclusões" sociais, econômicas e culturais. As transformações do mundo globalizado propõem o aparecimento de uma nova cultura individualista, resultando na formação de novos atores sociais. No entanto, mesmo que o modo de produção capitalista "determine" qual tipo de indivíduo formar, é importante destacar que o indivíduo não é apenas um ser biológico inserido em uma sociedade, independentemente de qual modelo esta seja.

Formar novos sujeitos sociais capazes de pensar e agir socialmente, ou ainda intervir de modo atuante no atual contexto de sociedade na qual vivemos - sociedade capitalista - é uma tarefa que requer da educação a adoção de uma postura perante as problemáticas sociais que surja a partir de novas formas de pensar e de atuação em ambientes cada vez mais complexos e globalizados.

A educação não é meramente uma atividade prática. A educação consiste na formação da capacidade física, moral e intelectual dos indivíduos, ou seja, é uma ação crucial para o desenvolvimento tanto humano quanto social das futuras gerações. Nesse sentido, entendemos que seu papel como propulsora para novas propostas de elaboração de estratégias para a mudança consciente dos educandos é fundamental, tendo em vista que estamos sob a égide do mundo capitalista. Segundo Mészáros "apenas a mais ampla das concepções de educação nos pode ajudar a perseguir o objetivo de uma mudança verdadeiramente radical, proporcionando instrumentos de pressão que rompam com a lógica do capital”. (MÉSZÁROS, 2005, p. 48).

Podemos destacar que o pensamento que possui uma concepção de indivíduo que vai além de uma visualização biológica, está pautado na concepção materialista da história ou na concepção do materialismo histórico, que é uma das características básicas do Marxismo. Essa concepção, na realidade, pode até indicar que o materialismo histórico é um método para se entender a natureza humana e seu caráter histórico, investigar as estruturas sociais e a história humana, bem como, a maneira como essas estruturas se formam e as mudanças que ocorrem no curso da história. 
A partir do campo do Marxismo, não mais o homem é apenas um ser integrante da natureza, este é um individuo inserido em uma sociedade regida por relações de produção. Este indivíduo é um produto histórico e social.

Podemos distinguir os homens dos animais pela consciência, pela religião, por tudo o que se quiser. Mas eles começam a distinguir-se dos animais assim que começam a produzir os seus meios de vida, passo este que é condicionado pela sua organização física. Ao produzirem os seus meios de vida, os homens produzem indiretamente a sua própria vida material. (MARX; ENGELS, 1984, p. 15).

O ponto de partida para conceituar indivíduo, a partir do pensamento marxista, é eliminar a ideia de homem abstrato, isolado da sociedade. Ao contrário, o homem é um ser social, e é na sociabilidade e na história que se torna humano. Ao nascer, o homem já está inserido em certas circunstâncias sociais e acaba sendo condicionado, o que não significa que seja passivo ou conformado com essas circunstâncias, pois este é um ser de criação, sendo que as condições são um produto seu, sendo a base material, a interatividade que cria as condições e meios para a realização própria de ser de cada singular.

Schaff (1967) retrata que o indivíduo, independentemente da classe social em que está inserido, é produto de relações sociais produzidas por esta, ou seja, a história dos homens e da sociedade está ligada ao modo e às relações sociais de produção em determinada sociedade. É a partir do modo de produção, que é o meio pelo qual entendemos como ocorre a formação material das sociedades, que subordina as atividades humanas e seus produtos. Através do trabalho é que o meio cria meios para a sua sobrevivência, modifica a si próprio e também a natureza.

A partir das premissas já citadas e do desenvolvimento deste trabalho, nesse momento, inquietações começam a surgir, como: o que diferencia o papel do educador e o papel de um oleiro, por exemplo? Podemos responder que a tarefa do educador é educar e a tarefa do oleiro é produzir vasos. Contudo, o produto resultante do trabalho do oleiro é o vaso, mas qual é o produto resultante do papel do educador? Para responder a essa pergunta é importante ressaltar que a educação implica na produção social dos indivíduos.

Mészáros (2005) indica que a concretização de certa concepção de educação que não faça parte das engrenagens capitalistas é uma das propostas de mudança que pode vir a ser um meio de rompimento com a lógica do capital. Sendo assim, 
o trabalho é o elemento-chave para entender como acontece a produção social dos indivíduos, bem como outros elementos como a alienação, por exemplo. O trabalho é uma das formas que o homem tem de criação de sua própria natureza. É o meio para o desenvolvimento humano, ao mesmo tempo é uma forma de dominância, porque é a partir dele que o homem modifica a natureza, a si mesmo e podemos dizer também, a vida de outros homens.

Pires (1997) ainda ressalta que o trabalho é a categoria central de análise da materialidade histórica dos homens porque é a forma mais simples, mais objetiva, que eles desenvolveram para se organizarem em sociedade. Logo, a base das interações sociais são as relações sociais de produção, as formas organizativas do trabalho.

É no processo e na produção social dos homens que é formado o indivíduo "real" que produz seu meio de subsistência, sua condição material. No entanto, o conceito de trabalho em sua origem não indica apenas uma forma de condição para o homem criar-se a si mesmo, este conceito se transformou em uma atividade "desumana".

\begin{abstract}
Alguns homens passaram a dispor de meios para explorar o trabalho dos outros; passaram a impor aos trabalhadores condições de trabalho que não eram livremente assumidas por estes. Introduziu-se, assim, um novo tipo de contradição no interior da comunidade humana, no interior do gênero humano. (KONDER, 1981, p. 29).
\end{abstract}

Foi a partir da divisão social do trabalho que surgiu o aparecimento das classes sociais. A divisão social do trabalho indica o grau de desenvolvimento de uma nação, determinando as relações dos indivíduos entre si. A partir desse momento, as relações de trabalho passam a ser contrastantes, quando o produto do trabalho não pertence ao trabalhador que o produziu, porque agora o trabalho é o meio de sobrevivência deste, ocasionando um afastamento entre o trabalhador e o trabalho.

Segundo Marx (1983), o trabalho não pertence a seu ser, é externo; o trabalhador não se afirma, se nega, não se sente feliz, não desenvolve sua energia física e espiritual, mortifica seu corpo e arruína seu espírito. Por isso só se sente em si fora do trabalho, e no trabalho fora de si; seu trabalho não é assim, voluntário, é forçado, gerando assim o processo de alienação. 
O trabalhador põe a sua vida no objeto; porém agora ele já não lhe pertence mas sim ao objeto. Quanto maior a sua atividade, mais o trabalhador se encontra objeto. Assim, quanto maior é o produto, mais ele fica diminuído. Quanto mais valor o trabalhador cria, mais sem valor e mais desprezível se torna. Quanto mais refinado é o produto mais desfigurado o trabalhador (MARX, 2002, p. 112).

O conceito de alienação em Marx torna-se complexo por envolver várias dimensões: a relação do trabalhador com o produto do seu trabalho, com o trabalho em si, a relação com o ser genérico, com o outro trabalhador e finalmente consigo mesmo, no entanto, trazendo elementos para identificarmos de forma simples, mais clara, o que venha a ser a alienação. A alienação, em seu sentido amplo, é considerada a primogênita de todas as outras alienações, como a alienação econômica e a alienação intelectual.

Partindo da crítica marxista sobre a noção de indivíduo, como ser social e histórico, destacaremos uma das perspectivas educacionais a qual referenciamos, frisando que o objetivo deste trabalho não é impor a "verdade" ou apresentar respostas definitivas, mas, contribuir reflexivamente sobre o papel da educação frente à sociedade capitalista. Mesmo que o tema educação não tenha um tratamento específico em Marx, no conjunto de suas ideias, o pensamento marxista traz contribuições de extrema importância para a educação, conforme já abordado.

O sujeito histórico é permeado pela educação. O educar é o meio pelo qual o homem se constrói historicamente. No entanto, no interior da ordem capitalista, educadores e alunos são considerados em termos daquilo que podem produzir; as produções são consideradas como valiosas, como as notas, os exames, as qualificações. Os educadores acabam sendo considerados como meros trabalhadores e mercadorias em produção. Pensando na escola, o aluno tem o seu potencial de trabalho. Ao trocar o seu produto por objetos na forma de notas e certificados, podemos compará-los aos salários, ou recompensas.

A escola é produtora de sujeitos sociais e a sua função não deve ser ou não deveria ser a de camuflagem ou legitimização de uma ideologia de função social e produção de indivíduos programados para a continuidade social do sistema capitalista. Nesta perspectiva, nos parece ser impossível que a escola seja um "veículo" para a não formação de futuros trabalhadores "alienados", porque no campo educacional o educador também é um trabalhador comum e seus alunos, meros produtos capitalistas. No entanto, a superação da alienação capitalista, segundo Marx, só se concretizará com o comunismo. O comunismo é a resposta para a superação das condições atuais do homem. 
Assim, a importância acerca do papel da educação é de extrema importância para efetivar o seu papel, como Marx e Engels definem:

A doutrina materialista sobre a alteração das circunstâncias e da educação esquece que as circunstâncias são alteradas pelos homens e que o próprio educador deve ser educado. Ela deve, por isso, separar a sociedade em duas partes - uma das quais é colocada acima da sociedade. A consciência da modificação das circunstâncias com a atividade humana ou alteração de si próprio só pode ser apreendida racionalmente como práxis revolucionária. (MARX; ENGELS, 1993, p. 12).

A partir do pensamento de Gadotti (1995), entendemos que a força da educação está no seu poder de mudar comportamentos. Mudar comportamentos significa romper com certas posturas, superar dogmas, desinstalar-se, contradizer-se, ou seja, a força da educação está na ideologia. É na práxis revolucionária que o educador dialeticamente se constrói, enquanto agente de construção do educando, sua atuação está atrelada ao seu posicionamento político, sociocultural e ideológico.

Perguntas como: o que a educação pode oferecer? O que nós queremos da educação? São de suma importância para concretizar uma práxis transformadora.

É notório que uma educação seja alvo da dominação incessante da classe dominante, e que de forma sutil cria mecanismos camuflados para que a sociedade conviva com o sistema de ensino voltado à dominação da classe menos favorecida. No entanto, reconceituar as dimensões histórica, cultural e política nas atividades práticas do trabalho articuladas a situações concretas das práticas sociais é um dos meios para a visualização de outras posturas educacionais. Uma educação que não seja meramente para formação de futuros "alienados", mas sim, uma educação que não se conforme com a reprodução social e que leve em consideração o caráter sócio-histórico do indivíduo é fundamental.

A educação não é um mero ato, é absolutamente necessária ao homem para que este seja homem na dimensão histórico-social e de práxis. Assim, precisamos "reinventar" a educação, mostrar para a sociedade capitalista que somente através de uma nova perspectiva é que teremos possibilidade de melhoria de vida, difundir novas ideias e fazer com que a escola não seja apenas uma etapa a ser percorrida em nossa existência, mas sim uma forma de nos tornarmos humanos. 
Considerando que os homens se caracterizam por um vir a ser, a relação entre os homens não está dada, mas precisa ser construída (vir a ser), construída material (trabalho social) e historicamente (organização social do trabalho). O trabalho, como princípio educativo, traz para a educação a tarefa de educar pelo trabalho e não para o trabalho, isto é, para o trabalho amplo, filosófico, trabalho que se expressa na práxis (articulação prática com a dimensão teórica pensada). (PIRES, 1997, p. 91).

Em suma, a perspectiva educacional à qual nos referimos é aquela que possibilite aos indivíduos a construção autônoma de sua subjetividade, resultando em pessoas singulares, o que seria um empreendimento verdadeiramente revolucionário, uma reação contra a sociedade de dominação que vem fazendo de nós parte de suas engrenagens por muito e muito tempo.

\section{REFERÊNCIAS}

GADOTTI, Moacir. Pedagogia da Práxis. São Paulo: Cortez, Instituto Paulo Freire, 1995.

KONDER, Leandro. O que é Dialética. São Paulo: Ed. Brasiliense, 1981.

MARX, Karl; ENGELS, Friedrich. A ideologia alemã. 9. ed. São Paulo: Hucitec, 1993.

MARX, Karl. Manuscritos econômico-filosóficos. São Paulo: Martin Claret, 2002. . Manuscritos Econômico-Filosóficos. Lisboa: Edições 70, 1989.

. O Capital. São Paulo, Livro I, v. 01, 1983. (Série Os economistas).

MARX, Karl; ENGELS, Friedrich. A ideologia alemã: teses sobre Feuerbach. São Paulo: Moraes, 1984.

MÉSZÁROS, István. A educação para além do capital. São Paulo: Boitempo, 2005. 
PIRES, Marília Freitas de Campos. O materialismo histórico e a educação. Interface: Comunicação, Saúde, Educação, São Paulo, v.1, n.1, 1997.

SCHAFF, Adam. A concepção marxista do indivíduo. Rio de Janeiro: Civilização Brasileira, 1967.

Texto recebido em 22 de abril de 2009.

Texto aprovado em 16 de setembro de 2009. 